- Compares referrals for the removal of third molars.

- Similarities were found in age and gender as well as reasons for referral.

- The dental hospital studied had a greater tendency to conservative management.

- The specialist practitioner studied dealt with greater patient numbers over a shorter time frame and was better at predicting the extent of surgery.

- Access to such a specialist in surgical dentistry offers advantages to both dentists and patients.

\title{
Indications for and anticipated difficulty of third molar surgery: A comparison between a dental hospital and a specialist high street practice
}

\author{
M. Macluskey, ${ }^{1}$ M. Slevin, ${ }^{2}$ M. Curran ${ }^{3}$ and R. Nesbitt ${ }^{4}$
}

\begin{abstract}
Objective To investigate the indications for and anticipated difficulty of third molar surgery between two different referral settings.

Design A prospective study involving completion of a proforma pre- and post-operatively.

Setting A dental teaching hospital and a specialist surgical dentistry practice in 2003.

Subjects and methods Patients referred for the assessment of their third molars were recruited. Details of the clinical and radiographical assessment for each patient were recorded pre-operatively and the extent of surgery required post-operatively.

Results The main indication for referral for third molar extraction was pericoronitis in both centres. A larger number of patients were assessed and treated in a shorter period of time at the surgical dentist compared with the dental hospital. The surgical dentist was accurate in his assessment of the difficulty of surgery $96 \%$ of the time compared with $66 \%$ for the dental hospital staff.

Conclusions This study highlights the benefits for patients in being treated by a surgical dentist. As dental students require exposure to surgical dentistry in order to attain a level of competence, a reduction in the number of patients being referred to dental hospitals may impact upon students' ability to both assess and perform surgical procedures. This may mean that undergraduates will be less able to fulfil the recommendations of the General Dental Council. ${ }^{1}$ An outreach programme for final year dental students to surgical dentistry practices would benefit all concerned.
\end{abstract}

\section{INTRODUCTION}

The extraction of third molars is the most common surgical procedure in dentistry. The dissemination of national guidelines for

\footnotetext{
${ }^{{ }^{*}, 4}{ }^{4}$ Clinical Lecturers in Oral Surgery, University of Dundee Dental Hospital and School, Park Place, Dundee, DD1 4HR; ${ }^{2}$ Vocational Trainee, Main Street, Prestwick, Aryshire, KA9 1JN: ${ }^{3}$ Specialist in Surgical Dentistry, Lisburn Road, Belfast, County Antrim, BT9 6GR *Correspondence to: Dr Michaelina Macluskey Email:m.macluskey@dundee.ac.uk
}

\section{Refereed paper}

Accepted 22 Feb 05

doi: $10.1038 /$ sj.bdj.4812931

$\odot$ British Dental Journal 2005; 199: 671-675 the referral of patients for third molar removal has reduced the numbers of referrals for the prophylactic removal of third molars with a decreasing trend for referrals for hospital based services in England and Wales since 1997. ${ }^{2}$ This, in turn, has meant a reduction in the numbers of third molars removed. ${ }^{3}$

Referrals for dentoalveolar surgery are commonly made due to the perceived difficulty of surgery, complicated medical histories and/or a lack of general anaesthetic facilities. ${ }^{4}$ The usual referral centre is the nearest district general hospital. However, many GDPs would refer to a specialist depending upon geographic location and patient preference with the expectation of reduced waiting times and improved convenience. ${ }^{5,6}$

The teaching of guidelines, the assessment of third molar and other tooth impactions, and management form an important component of the undergraduate oral surgery curriculum. However, despite the guidance from the GDC regarding the requirements for competence in oral surgery as outlined in the First five years, ${ }^{1}$ the actual experience of surgical dentistry as an undergraduate varies both within and between dental institutions throughout the UK. Thus, confidence in an individual's ability based on training and experience is often undermined. This has a bearing on referral patterns in that inexperienced GDPs have a greater tendency for referral with the expectation that general anaesthesia may be required. ${ }^{6}$ In contrast, those practitioners that have had postgraduate experience of oral and maxillofacial surgery have a greater tendency to perform dentoalveolar surgery in practice, while having a lower threshold for referral of more complicated cases. ${ }^{5}$

A thorough history, clinical assessment and radiographic examination are required in order to decide upon an appropriate treatment plan. Informed consent relies upon an appropriate assessment of the likely extent of surgery based on the clinical and radiographic findings such as depth, degree of impaction, ramus relationship/space available, width of root or a combination of these factors. ${ }^{7}$ A number of indices to determine the degree of difficulty have been devised to attempt to address this issue. ${ }^{7-9}$ However these do not take into account patient factors that are also important variables. ${ }^{10}$ In addition, such indices have been found to be unreliable for predicting the difficulty of surgery. ${ }^{11}$ 


\begin{tabular}{|c|c|}
\hline \multicolumn{2}{|l|}{ Details recorded for new third molar referrals } \\
\hline Grade of clinician & $\begin{array}{l}\text { SHO, Staffgrade, Associate } \\
\text { Specialist, Consultant }\end{array}$ \\
\hline Reason for referral & $\begin{array}{l}\text { Prophylactic removal, } \\
\text { pericoronitis, caries food trapping, } \\
\text { pathology, other }\end{array}$ \\
\hline Tooth indicated in referral & LR8, LL8, UR8,UL8 \\
\hline Clinical stage of eruption & $\begin{array}{l}\text { Fully erupted, partially erupted, } \\
\text { unerupted }\end{array}$ \\
\hline $\begin{array}{l}\text { Radiographic examination } \\
\text { - Angle } \\
\text { - Depth } \\
\text { - Root morphology }\end{array}$ & $\begin{array}{l}\text { MA, DA, V, H } \\
\text { Superficial, moderate, deep } \\
\text { Simple, bulbous, convergent, } \\
\text { divergent, other }\end{array}$ \\
\hline Management & $\begin{array}{l}\text { Conservative, simple extraction, } \\
\text { surgical removal }\end{array}$ \\
\hline Indication for management & $\begin{array}{l}\text { None, pericoronitis, caries in } 8, \\
\text { caries in 7, trauma, other }\end{array}$ \\
\hline Estimate of difficulty of third molar removal & $\begin{array}{l}\text { Simple elevation/ extraction [1] } \\
\text { Soft tissue flap required but no } \\
\text { bone removal [2] } \\
\text { Surgical with bone removal [3] } \\
\text { Difficult requiring much bone } \\
\text { removal and piecemeal removal of } \\
\text { tooth [4] }\end{array}$ \\
\hline Anaesthetic & LA, LA/IV sedation, GA \\
\hline Length of wait for treatment & [reasons for delay?] \\
\hline Method of removal & 1 - 4 [same as above estimate] \\
\hline Grade of operator & $\begin{array}{l}\text { Student, SHO, Staffgrade, } \\
\text { Associate Specialist, Consultant }\end{array}$ \\
\hline Complications & $\begin{array}{l}\text { Failed LA, Haemorrhage, dry } \\
\text { socket, infected socket, transient } \\
\text { nerve damage, long-term nerve } \\
\text { damage }\end{array}$ \\
\hline
\end{tabular}

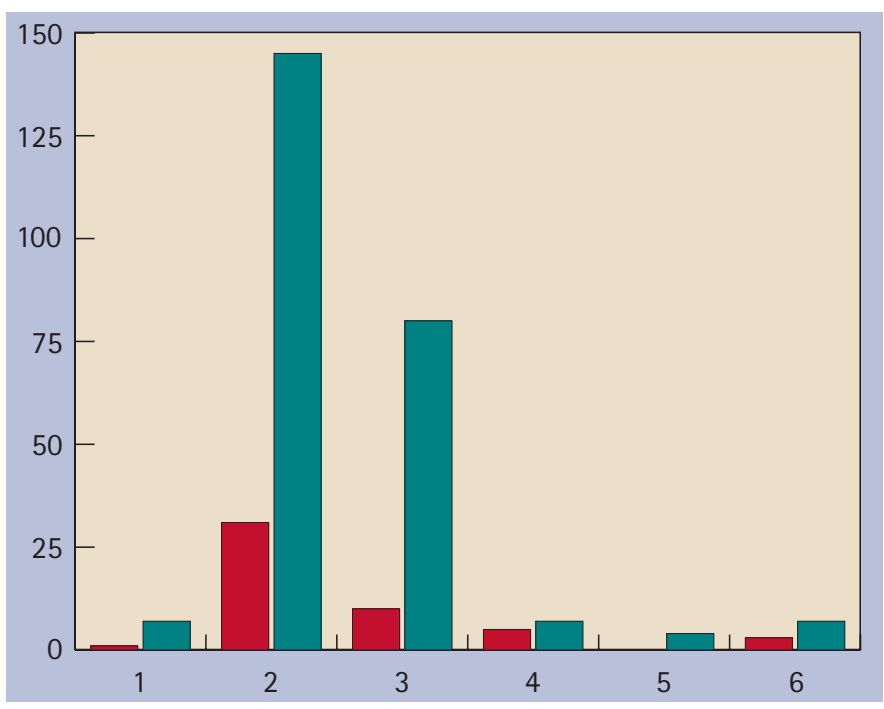

Fig. 1 Reason for referral

$1=$ prophylactic removal, $2=$ pericoronitis, $3=$ caries, $4=$ food trapping,

$5=$ pathology, $6=$ other reason, $\mathrm{DH}=$ red, $\mathrm{SD}=$ green, $\mathrm{Y}$ axis in all graphs $=$ numbers of teeth

The aim of this study was to investigate the differences in the referral pattern, assessment and subsequent management of third molars in both a dental hospital (DH) and a specialist surgical dentistry practice (SD). A secondary aim was to determine the accuracy of the estimation of surgical difficulty by the staff involved in each establishment.

\section{MATERIALS AND METHODS}

A two site prospective study was undertaken over a period of four months from January until April 2003 at the DH and over the summer months at the SD as this was undertaken as part of an undergraduate elective project. As Tayside does not have a specialist surgical dentistry high street practice, a specialist practitioner in Belfast who has close links with the DH agreed to take part in the study. Patients referred for the assessment of their third molars were recruited to the study. At the DH this involved the participation of a number of staff in the assessment and subsequent management of the patients, whereas only one individual was involved in the specialist practice. A proforma was designed to record the demographic data, in addition to a number of details pertinent to the assessment of third molars both clinically and radiographically (Table 1 ). The same proforma was used at both sites. Rather than use one of the indices of surgical prediction discussed in the introduction, the authors preferred that the clinicians who agreed to take part in this work instinctively estimated the surgery required by broadly dividing the patients into those who would require one of the following: simple extraction (1); soft tissue flap only (2); soft tissue flap and bone removal (3); bone removal and tooth sectioning (4). On completion of treatment the proformas were completed with reference to the patients' notes by one individual particularly taking details of the actual extent of surgery performed, grade of surgeon involved, the length of time from assessment until treatment and complications experienced by the patient.

\section{RESULTS}

The intention was to recruit 50 patients from each establishment, commencing January 2003 at the DH and over the summer months at the SD. As patients at the DH could only be recruited from a few clinics per week at the $\mathrm{DH}$, the cases were recruited over a four month period. In contrast, 250 patients were seen by the surgical dentist over the month of July. Of the 50 patients (with 67 teeth) referred to the $\mathrm{DH}, 39$ were female and the average age was 33 years. At the SD again the majority of the 250 patients (with 290 teeth) were female (149 patients) and the average age was 26 years. A greater proportion of referrals were made by medical practitioners to the $\mathrm{DH}$ than to the SD.

A summary of the comparison between the DH and the SD is shown in Table 2. The commonest reason for referral for third molar extraction was pericoronitis, with 58\% and 62\% for the SD and the DH respectively. Caries was the second highest reason for referral, with 20\% and 32\% of cases. A small number of patients were seen for pathological, prophylactic, food trapping or other reasons, namely cheek biting (Fig. 1). The main indication for management was pericoronitis followed by caries but in some cases there was no indication for management (Fig. 2).

The majority of impacted third molars were partially erupted although there was a greater percentage of patients with unerupted third molars at the DH - 15\% compared with 1\% - but this may reflect the difference in sample size (Table 2).

The commonest angle of impaction of the third molar was vertical at the SD compared with mesio-angular impactions at the DH, mainly superficially placed at both sites. There was a marked discrepancy between the centres regarding the root morphology, as the SD observed more convergent roots (193 of the actual teeth assessed) compared with simple root morphologies (38 of the actual teeth assessed) at the $\mathrm{DH}$.

The DH treated 28\% of cases conservatively, whereas it was not considered appropriate for the cases assessed by the SD. At the SD $70 \%$ of extractions were managed surgically and the rest were described as simple extractions. The DH treated 57\% surgically and $15 \%$ by simple extraction.

Forty-two per cent of patients from the DH were treated under local anaesthetic, 35\% with IV sedation and 23\% with GA. In the 
SD 33\% were treated by local anaesthetic alone and 67\% with IV sedation and local anaesthetic and no patients required GA.

The experience of staff (and in some cases students) varied in the $\mathrm{DH}$ in both the assessment and treatment of the patients (Fig. 3). In the majority of cases the assessment and subsequent treatment of the patient were carried out by a different member of staff, with the staff grades performing the majority of the work. In contrast, the same individual was responsible for the assessment and treatment of all of the patients at the SD.

The SD was accurate in his assessment of the difficulty of the surgery, correctly predicting the extent of surgery $96 \%$ of the time (Fig. 4). The commonest reason for the small level of inaccuracy was the requirement for a soft tissue flap to be raised rather than a simple extraction. The predictive ability of the DH staff was $66 \%$, with equal incidences of under and over estimation of the degree of surgical difficulty. However no direct relationship was found between predictive ability and level of experience possibly due to the relatively small numbers. The waiting list for treatment at the SD was three to four weeks compared with over six months in some cases at the DH (Fig. 5). The reason for the longer waiting time was the requirement for general anaesthesia.

Six patients experienced post-operative complications such as haemorrhage, dry socket, wound infection or a transient alteration in sensation after their treatment. Interestingly all of these cases were treated by the same clinician. None of the SD patients returned with any post-operative complications.

\section{DISCUSSION}

The potential establishment of specialist lists has led to confusion, both for patients and practitioners, as to which is the most appropriate route for referral, especially with respect to ease of access and within a respectable time frame. ${ }^{12}$ At a time when the future of the surgical dentistry specialist list is in the spotlight, this study

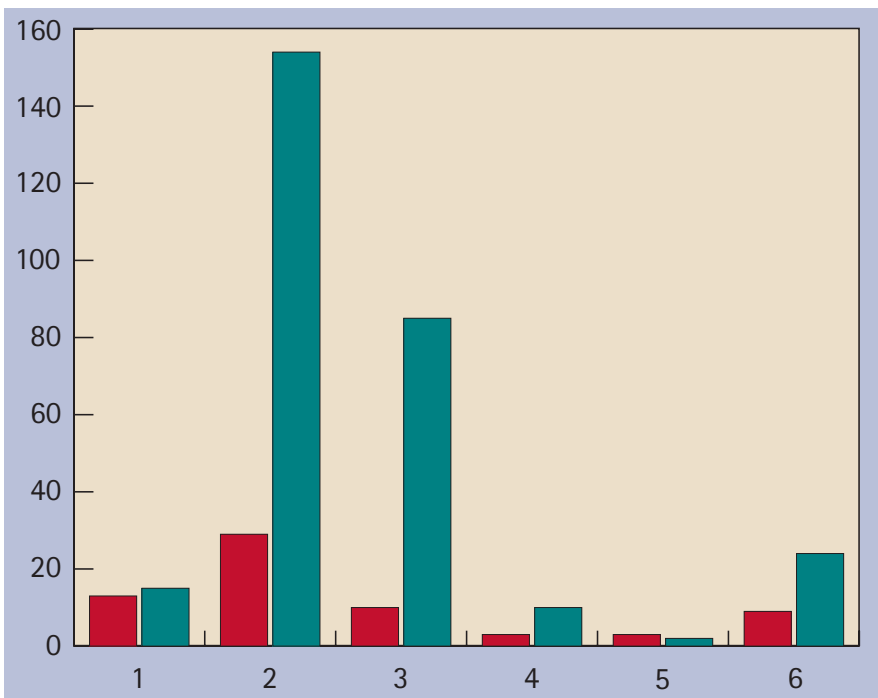

Fig. 2 Indication for active management

$0=$ no indication, $1=$ pericoronitis, $2=$ caries in wisdom tooth, $3=$ caries in adjacent tooth, $4=$ trauma, $5=$ other, $\mathrm{DH}=$ red, $\mathrm{SD}=$ green

underlines the advantages of having a specialist in surgical dentistry in high street practice. Such an individual may soon be referred to as a dental practitioner with specialist interest. ${ }^{13}$

Not surprisingly there were a number of similarities between the DH and the SD particularly with regard to patients' age and gender. However, a considerable difference in sample size was found within a short time period between the two sites, highlighting the throughput and turnover of cases in a specialist practice. The reasons for referral of third molar cases generally conformed to national guidelines regarding referral for the removal of third molars. However, it would seem that there was a slight tendency

\begin{tabular}{|c|c|c|}
\hline Comparison & Dental hospital & Specialist practice \\
\hline $\begin{array}{l}\text { Patients } \\
\text { - Gender } \\
\text { - Age } \\
\text { - Number of teeth }\end{array}$ & $\begin{array}{l}50 \\
11 \mathrm{M}: 39 \mathrm{~F} \\
18-69, \text { mean } 33 \text { years } \\
67\end{array}$ & $\begin{array}{l}250 \\
101 \mathrm{M}: 149 \mathrm{~F} \\
17-75, \text { mean } 26 \text { years } \\
290\end{array}$ \\
\hline Reason for referral & Pericoronitis 58\% & Pericoronitis $62 \%$ \\
\hline $\begin{array}{l}\text { Stage of eruption } \\
\text { - Fully erupted } \\
\text { - Partially erupted } \\
\text { - Unerupted }\end{array}$ & $\begin{array}{l}25 \% \\
60 \% \\
15 \% \\
\end{array}$ & $\begin{array}{l}28 \% \\
71 \% \\
1 \% \\
\end{array}$ \\
\hline $\begin{array}{l}\text { Radiographic Assessment } \\
\text { - Angle } \\
\text { - Depth } \\
\text { - Root morphology }\end{array}$ & $\begin{array}{l}\text { commonest } \\
\text { MA 45\% } \\
\text { Superficial } 60 \% \\
\text { Simple } 57 \%\end{array}$ & $\begin{array}{l}\text { commonest } \\
\text { V } 67 \% \\
\text { Superficial } 76 \% \\
\text { Convergent } 67 \%\end{array}$ \\
\hline $\begin{array}{l}\text { Management } \\
\text { - Conservative } \\
\text { - Simple extraction } \\
\text { - Surgical removal } \\
\end{array}$ & $\begin{array}{l}28 \% \\
15 \% \\
57 \% \\
\end{array}$ & $\begin{array}{l}0 \% \\
30 \% \\
70 \%\end{array}$ \\
\hline $\begin{array}{l}\text { Anaesthetic } \\
\text { - LA } \\
\text { - LA/IV sedation } \\
\text { - GA }\end{array}$ & $\begin{array}{l}42 \% \\
35 \% \\
23 \%\end{array}$ & $\begin{array}{l}30 \% \\
70 \% \\
0 \%\end{array}$ \\
\hline $\begin{array}{l}\text { Anticipated difficulty } \\
\text { - } 1 \\
\text { - } 2 \\
\text { - } 3 \\
\text { - } 4 \\
\end{array}$ & $\begin{array}{l}33 \% \\
12 \% \\
45 \% \\
10 \% \\
\end{array}$ & $\begin{array}{l}26 \% \\
11 \% \\
36 \% \\
27 \% \\
\end{array}$ \\
\hline $\begin{array}{l}\text { Actual Difficulty } \\
\text { - } 1 \\
\text { - } 2 \\
\text { - } 3 \\
\text { - } 4 \\
\end{array}$ & $\begin{array}{l}33 \% \\
6 \% \\
40 \% \\
21 \% \\
\end{array}$ & $\begin{array}{l}24 \% \\
13 \% \\
37 \% \\
26 \% \\
\end{array}$ \\
\hline Complications & $13 \%$ & $0 \%$ \\
\hline
\end{tabular}




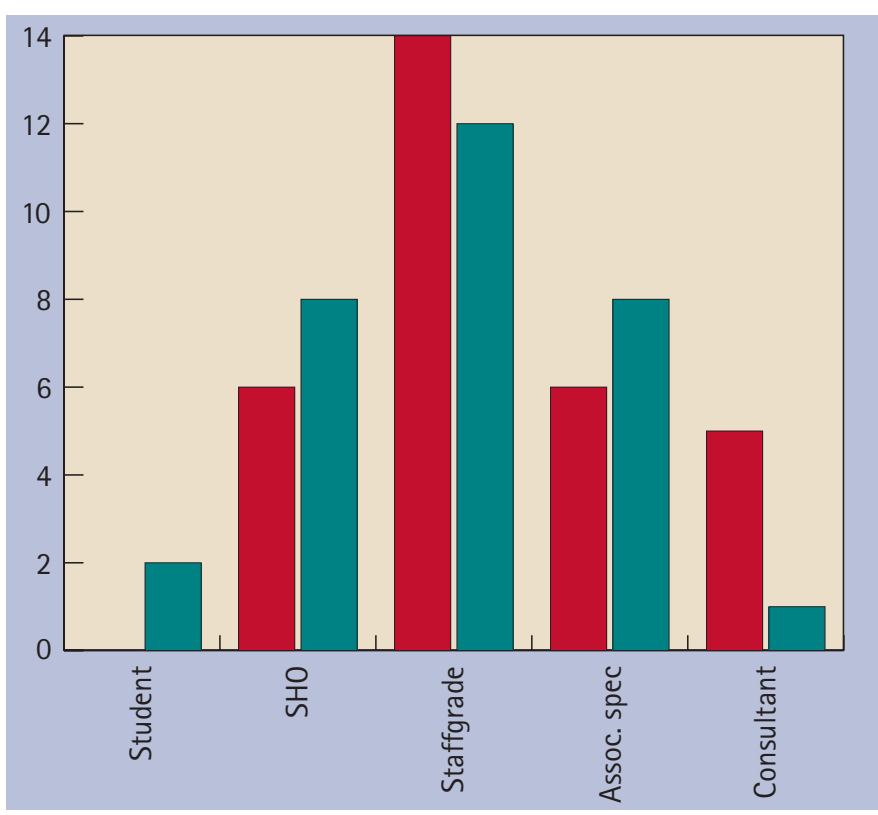

Fig. 3 Staff involved in the assessment and management of wisdom teeth Initial assessment performed by each group $=$ pink

Actual surgical treatment performed by each group $=$ green

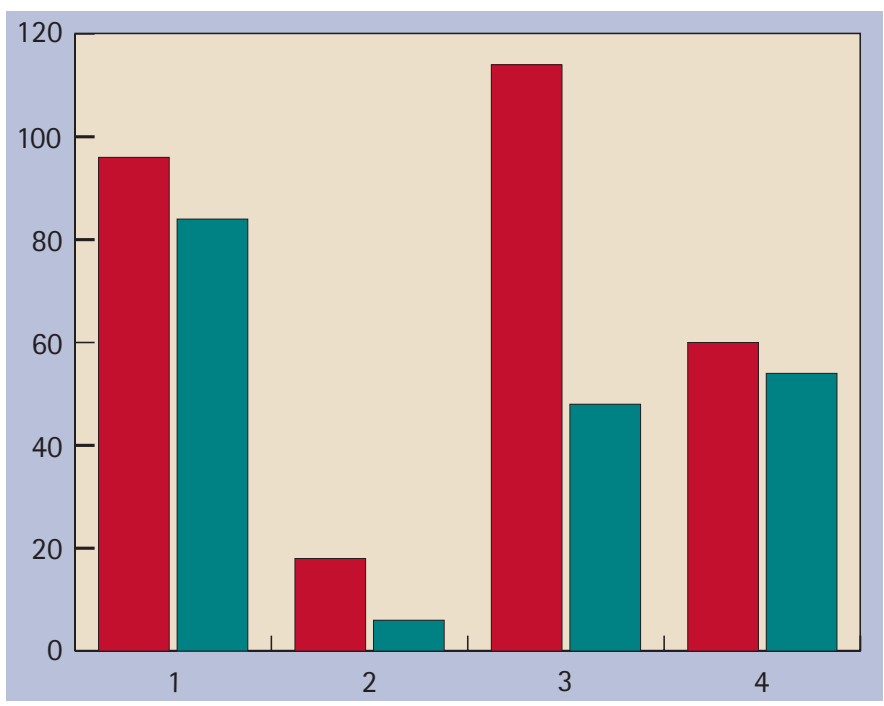

Fig. 4 Anticipated versus actual difficulty of surgery as per SD

1 = simple extraction, 2 = flap but no bone removal, 3 = surgical with bone removal,

$4=$ difficult requiring bone removal and tooth/ root sectioning.

Red $=$ anticipated, green $=$ actual [96\% accurate]

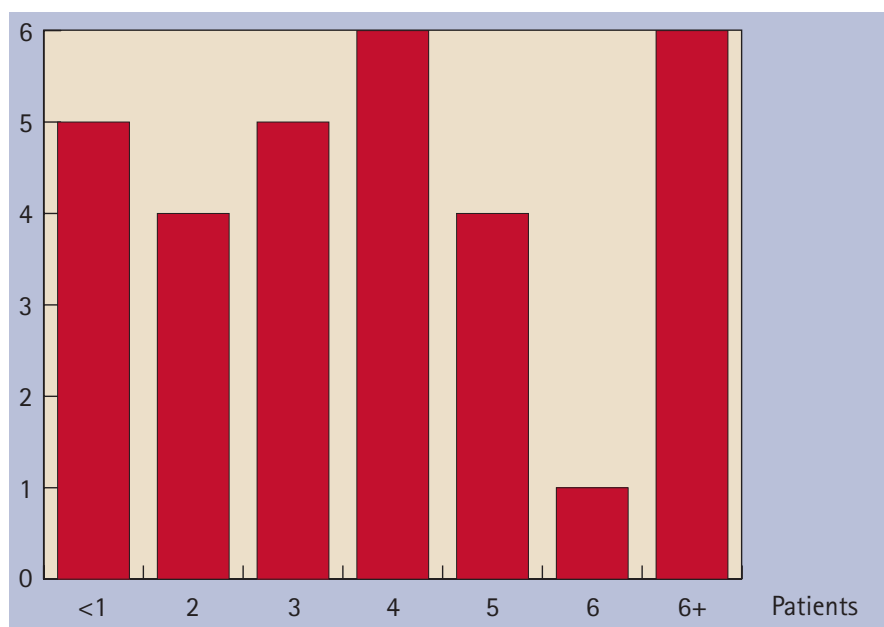

Fig. 5 Length of waiting time (months) until treatment at the $\mathrm{DH}$

The $y$ axis indicates the number of patients and the $x$ axis the number of months waited for treatment. to the prophylactic removal of non-functional maxillary third molars at the SD. Most concerns of referring practitioners relate to lack of availability. ${ }^{14}$ This study has highlighted the difference in the waiting time, which in this case is for treatment rather than initial consultation. This was longer at the DH possibly because the appointment time allocated for each case is standardised to allow for teaching as well as the provision of high quality care, thus a smaller number of cases are managed per session compared with the SD. The ability to predict the surgical difficulty by the SD would allow more efficient time management and therefore a higher turnover of cases. In addition, this would allow more focused patient preparation which would impact positively upon patient satisfaction and post-operative pain control. ${ }^{15}$ The reduced predictive ability of the DH staff could be a function of experience, but with such small numbers at the DH no firm conclusions can be made. This inexperience may also affect the resultant complication rate found at the DH. ${ }^{16}$ The length of the waiting list at the DH was compounded by those patients requiring GA. It could be argued that this may be because the SD cases were surgically more straightforward and less medically compromised than those referred to the DH. ${ }^{6}$ However, Sadler et al. ${ }^{17}$ found that surgical complexity was not a contraindication to practice treatment but some patients may be better treated in hospital because of medical or social circumstances. Another study found that many patients referred for dental hospital treatment because of an underlying medical condition were not in fact medically-compromised and could have been treated in the primary care setting. ${ }^{18}$ This work suggests that no significant differences were found in the actual surgical difficulty between the two sites as both dealt predominantly with superficially placed teeth. The DH removed more mesioangular impacted teeth with simple root morphology, whereas the SD removed more vertically impacted teeth with convergent roots. However the SD had to section a higher proportion of teeth than the $\mathrm{DH}$ which may indicate more involved surgery.

Further work on larger sample sizes could be done to specifically address patient satisfaction between a SD and a DH. The disparity in sample size in this work may contribute to inaccurate deductions about the influence of clinical experience in both the assessment and treatment and therefore predictive ability. The medical status of the patient should also be taken account of as this may have a bearing on type of anaesthesia and appropriate venue for treatment.

It could be queried that if only $13 \%$ of the DH patients required a GA, for whatever reason, could the other $83 \%$ of patients not have been seen at a surgical practice? These patients would have experienced the benefits of a high street practice. Following on from this, of the 300 patients seen at both centres, only seven required in-patient treatment, so should general dental and medical practitioners be encouraged to use the high street practice as the primary referral site and the surgical dentist then make the decision to refer on to the hospital setting? This would help to reduce the burden on busy maxillofacial units within district general hospitals. In addition those patients requiring general anaesthesia could be referred directly to a day case surgery list reducing waiting times for the patients thus improving satisfaction. ${ }^{19}$ However, such a system would impact on the teaching of surgical dentistry to undergraduates.

This study highlights that from a patient's point of view there are advantages to being treated by a SD, namely reduced waiting times for treatment, both assessment and treatment by the same clinician, a high predictive ability to allow appropriate preparation for surgery, and fewer post-operative complications.

Future developments could include an outreach programme for final year students to allow students to increase their exposure to surgical dentistry and sedation and appreciate what can be done in 
a practice environment, which should prove to be beneficial. ${ }^{20}$ This may then in turn influence referral patterns.

The authors would like to thank all the members of staff within the Oral Surgery Department of the University of Dundee Dental Hospital and School who completed the initial assessment of the patients involved in this work.

1. General Dental Council. The first five years - A framework for dental undergraduate education. 2002. www.gdc-uk.org/ publications.htm

2. Jamileh Y, Pedlar J. Effect of clinical guidelines on practice for extraction of lower third molars: study of referrals in 1971 and 2000. Br J Oral Maxillofac Surg 2003; 41:371-375.

3. Sheldon T A, Cullun N, Dawson D, et al. What's the evidence that NICE guidance has been implemented? Results from a national evaluation using time series analysis, patients notes, and interviews. Br Med J 2004; 329: 999

4. Coulthard P, Kazakou I, Koran R, Worthington HV. Referral patterns and the referral system for oral surgery care. Part 2: The referral system and telemedicine. Br Dent J 2000; 188: 388-391.

5. Clark S. Professional attitudes to specialisation and minor oral surgery in genera dental practice. Br Dent J 1995: 176: 209-213.

6. Coulthard P, Kazakou I, Koran R, Worthington H V. Referral patterns and the referral system for oral surgery care. Part 1: General dental practitioner referral patterns. BrDent J 2000: 188: 142-145.

7. Yuasa $H$, Kawai T, Sugiura M. Classification of surgical difficulty in extracting impacted third molars. Br J Oral Maxillofac Surg 2002; 40: 26.

8. Pell G J, Gregory B T. Impacted third molars; classification and modified techniques for removal. Dent Dig 1993: 39:330.

9. Pedersen G W. Oral Surgery. Philadelphia: WB Saunders, 1988. In Koerner K R. The removal of impacted third molars - principles and procedures. Dent Clin North Am 1994; 38: 261.

10. Renton T, Smeeton N, McGurk M. Factors predictive of difficulty of third molar surgery. BrDent J 2001; 190: 607-610.

11. Garcia A G, Sampedro F G, Rey J G, et al. Pell-Gregory classification is unreliable as a predictor of difficulty in extracting impacted lower third molars. Br J Oral Maxillofac Surg 2000; 38: 585-587.

12. A review of the dental specialties and specialist lists. Interim report of a working group commissioned by the Chief Dental Officer for England. 2003. www.gdcuk.org/publications.html

13. Modernisation Agency. Practitioners with special interests. April 2003 www.natpact.nhs.uk/special_interests www.gpwsi.org

14. Crawford A N. The future provision of specialist oral surgery and orthodontic services. Br Dent J 1994; 177: 143-145.

15. Vallerand $W$ P, Vallerand $A H$, Heft M. The effects of postoperative preparatory information on the clinical course following third molar extraction. J Oral Maxillofac Surg 1994; 52: 1165-1170.

16. Sisk A L, Hammer W B, Shelton D W, Joy E D Jr. Complications following removal of impacted third molars: the role of the experience of the surgeon. J Oral Maxillofac Surg 1986; 44: 855-859

17. Sadler A, Davidson M, Houpis C, Watt-Smith S. Specialist practice for minor ora surgery: a comparative audit of third molar surgery. Br Dent J 1993; 174: 273-277.

18. Absi E G Satterthwaite J, Shepherd J P, Thomas D W. The appropriateness of referral of medically compromised dental patients to hospital. Br J Oral Maxillofac Surg 1997; 35: 133-136

19. Joshi A, Doyle L, Worthington H V, Rood J P. Direct access day case oral surgery. BrDent J 2000: 188: 452-456.

20. Lennon M A, Ireland RS, Tappin J et al. The personal dental service as a setting for an undergraduate clinical programme. Br Dent J 2004 10; 196: 419-422. 